\title{
Rethinking Intergenerational Transmission(s): Does a Wellbeing Lens Help? The Case of Nutrition
}

\author{
Andy Sumner, Lawrence Haddad and Laura Gomez Climent
}

\begin{abstract}
The intergenerational transmission (IGT) of poverty is a well-established conceptualisation of how poverty is reproduced over time. IGT has been a popular approach but as currently constructed it tends to be overly deterministic, and to overly emphasise material assets. In contrast, 'wellbeing' is emerging as a complement to the more traditional ways of conceptualising and measuring poverty and deprivation around material consumption. Wellbeing extends attention from what people can do and be and adds how people feel about what they can do and be. Wellbeing is thus explicitly rather than inferentially about agency and also goes beyond the material to consider the relational and the subjective domains of life. So, can a wellbeing lens help us to rethink IGT? We use an application to an IGT mechanism: the transmission of undernutrition from one generation to the next.
\end{abstract}

\begin{abstract}
1 Introduction
This article seeks to address the following question: Can a 'wellbeing' approach or lens help us to rethink the intergenerational transmission of poverty and illbeing? The article is structured as follows. Section 2 discusses intergenerational transmission (IGT) and why a rethink is needed. Section 3 outlines and evaluates the contribution of a 'wellbeing' approach. Section 4 then considers IGT via a wellbeing lens in order to assess its value added in a general sense before applying it to an analysis of nutritional status - a key dimension of the IGT of illbeing/wellbeing (in section 5). Section 6 concludes.
\end{abstract}

\section{Why do we need to rethink IGT?}

The intergenerational transmission of poverty is a well-established conceptualisation of how poverty is transmitted from one generation to another (Castañeda and Aldaz-Carroll 1999: 2; Bird 2007: 1). IGT is often conflated with the dynamics of poverty literature. Poverty dynamics and IGT are both temporal and about how people move in and out of poverty over time. But IGT is specifically about poor adults having poor children rather than poor children becoming poor adults or poor adults staying poor.
Most work on IGT has tended to be on American societal and income mobility or state benefits dependency because large-scale longitudinal household data is available annually from 1968-89 from the American Panel Study of Income Dynamics (for details see Altonji et al. 1997). In contrast, there are virtually no longterm longitudinal panels from the developing world; hence the approach is much less well established in the development literature.

Moore (2001: 4) has developed the IGT concept along three dimensions:

- What exactly is transferred - typically thought to be capital: human, social-cultural, socialpolitical, financial/material and environmental/natural.

- How it is transferred - in terms of the unit of analysis (private transmission via families versus public transmission via community, state and market), and the direction of transmission (older generation to younger or also younger to older - sick children can make parents poor, for example, and transmission jumping from grandparents to grandchildren and vice versa). 
Table 1 What determines (individual) wellbeing?

\begin{tabular}{|c|c|c|}
\hline $\begin{array}{l}\text { Material - practical welfare } \\
\text { and standards of living }\end{array}$ & $\begin{array}{l}\text { Relational - personal and } \\
\text { social relations }\end{array}$ & $\begin{array}{l}\text { Subjective - values, } \\
\text { perceptions and experience }\end{array}$ \\
\hline Income, wealth and assets & Relations of love and care & $\begin{array}{l}\text { Understandings of the sacred } \\
\text { and the moral order }\end{array}$ \\
\hline $\begin{array}{l}\text { Employment and livelihood } \\
\text { activities }\end{array}$ & $\begin{array}{l}\text { Networks of support and } \\
\text { obligation }\end{array}$ & Self-concept and personality \\
\hline Education and skills & $\begin{array}{l}\text { Relations with the state: law, } \\
\text { politics, welfare }\end{array}$ & Hopes, fears and aspirations \\
\hline Physical health and (dis)ability & $\begin{array}{l}\text { Social, political and cultural } \\
\text { identities and inequalities }\end{array}$ & $\begin{array}{l}\text { Sense of meaning/ } \\
\text { meaninglessness }\end{array}$ \\
\hline Access to services and amenities & $\begin{array}{l}\text { Violence, conflict and } \\
\text { (in)security }\end{array}$ & Levels of (dis)satisfaction \\
\hline Environmental quality & $\begin{array}{l}\text { Scope for personal and } \\
\text { collective action and influence }\end{array}$ & Trust and confidence \\
\hline
\end{tabular}

Source White (2008: 11).

What determines transmission (or not) - and the role of economic/non-economic factors and internal/external household factors in transmission (shocks, socioeconomic trends, policy interventions, resilience) and whether the transfer or not of these capitals is necessary and/or sufficient to lead to the IGT of poverty.

Nevertheless, IGT in its current manifestation has three limitations:

1 It overemphasises the material (as opposed to the perceptual) basis of poverty, which is of course important but limiting.

2 It implies a certain level of determinism because of strong assumptions about agency for example, all preferences are pooled within the household, individuals tend to be predictably motivated by material incentives, and children are seen but not heard.

Relationships are not explicitly explored.

3 IGT is based on empirical evidence from Organisation for Economic Cooperation and Development (OECD) countries (and the USA in particular - see Bird's (2007) empirical review) and on correlations of parental and their (grown-up) children's income. This does not tell us much about the processes by which
IGT is disrupted, nor is it necessarily relevant for poor and emerging country contexts.

Can a wellbeing approach help address some of these limits?

\section{What is a wellbeing approach?}

'Wellbeing' is emerging as a complement to the more traditional and material ways of conceptualising and measuring poverty and deprivation. Wellbeing extends attention from what people can do and be and adds how people feel about what they can do and be. Wellbeing is thus explicitly about agency (what people can do and be rather than what they cannot) and also goes beyond the material to consider the relational and the subjective domains of life.

The Wellbeing and Development (WeD) group based at Bath University and partner organisations in Ethiopia, Bangladesh, Peru and Thailand have spent the past five years analysing 'wellbeing'. ${ }^{2}$ They conceive of wellbeing as

a combination of: i. what a person has, ii. what a person can do with what they have, and iii. how they think about what they have and can do ... [It] can be conceived in terms of the interplay of $i$. the resources that a person is able to command; ii. what they are able to achieve with those resources, and in particular 
what needs and goals they are able to meet, and iii. the meaning that they give to the goals they achieve and the processes in which they engage. (McGregor 2007: 317)

White (2008: 5) adds that,

Perhaps the signature move of a wellbeing approach is its direction of attention not only to external 'objective' measures of welfare but also to people's own perceptions and experience of life. At a simple level, this can be seen in terms of a contrast between the familiar 'objective' indicators of income, nutrition, life expectancy, etc. with the 'subjective' dimension of how individuals feel about their health or economic status.

The wellbeing approach builds on Sen's 'beings' and 'doings', focusing on the interactions between beings, doings and feelings. Table 1 summarises the approach. The material dimension of wellbeing concerns 'practical welfare and standards of living'. The relational concerns 'personal and social relations' and the subjective concerns 'values, perceptions and experience' (White 2008: 8). The wellbeing lens can take both the individual and the community as the unit of analysis. ${ }^{3}$

One could spend a long time debating the contents of this table. For example, the subjective-individual level includes values and aspirations. These might be better placed in a relational level. ${ }^{4}$ However our concern here is to identify where wellbeing itself as an approach adds value. The proposed value added is perhaps overdrawn - many contemporary definitions of poverty (e.g. human development, rights-based approaches, social exclusion approaches, sustainable livelihoods) go beyond income-based definitions of poverty and include more sociocultural and subjective dimensions of deprivation. However, the wellbeing approach does seem to provide value added over a 'traditional poverty' lens in at least two ways:

- Its explicit focus on the relational and the subjective. What people feel they can do or can be plays a strong role in what people will actually be able to be and do (take, for example, aspirations). In turn, these feelings and perceptions are determined by people's experiences as well as by the norms and values that are cultural and socially determined. The material, subjective and relational are co-evolving, interdependent and dynamically interacting domains. We cannot exclusively focus on just one or two of them.

- It is about positives. A wellbeing lens is more respectful, as it is based on what people can $\mathrm{do} / \mathrm{be} / \mathrm{feel}$, rather than deficits in what they can do/be/feel. In line with Nancy Fraser's work on recognition and respect, it avoids the 'Othering' (capital O) of people as the 'poor' and thus inferior to the 'non-poor'. It is also respectful in the sense that it is about selfdetermination and participation rather than exogenously defined wellbeing.

So, what do the sceptics say? The same two strengths are the two reasons a wellbeing approach is critiqued. These are:

Its holistic nature. 'Wellbeing' is seen as fuzzy and ambiguous as a concept. The word itself has become as maligned as words such as globalisation and sustainability. This criticism is inevitable given the attempt to be holistic i.e. to include everything and thus have to appeal to definitions of conceptual rigour across various disciplines - nevertheless the proponents of wellbeing must address it.

- It is about positives. The development community may be uncomfortable talking about 'positives' as it might seem to make light of deprivation as framed by Westerntrained researchers. The accusation is made that wellbeing makes poverty analysis apolitical. However, wellbeing's focus on the perceptual and relational is inherently political - who has what, who can do what, who feels good about what they can have and do, who commands resources, who is able to achieve their needs and goals with those resources and who constructs meanings in terms of goals to be achieved and processes to achieve those goals. It also makes power more explicit - not only as material political economy (e.g. Marx), but as discourse (e.g. Foucault), and as embedded in norms, values and conventions (e.g. North's institutions or Bordieu's habitus).

The operationalisation of a wellbeing approach in policy and practice is where much debate has now 
moved. The policy implications of the wellbeing perspective are discussed head-on by Copestake (2008: 776). He argues that wellbeing provides a common ground or 'mental map' or discursive space to discuss development across various perspectives - rights, livelihoods, exclusion, localled development and so on. ${ }^{5}$ Does it actually change the types of policies implemented - the what and the how, the for whom and the by whom? The wellbeing approach would suggest that public policy should have continued emphasis on the material wellbeing (public expenditure, growth, etc.). However, it requires stronger emphasis on more controversial public policy domains around values, relationships, norms and behaviour, recently popularised in Ariely (2008) and Thaler and Sunstein (2008) and more broadly in research in behavioural economics that is currently revolutionising economics (see Coyle 2007) and challenging a central tenet of mainstream economics, homo economicus - 'the notion that each of us thinks and chooses unfailingly well' (Thaler and Sunstein 2008: 6). Instead, human beings are very much influenced by their context and respond to that context or their 'choice architecture' or the organisation of that context in which people make their decisions (ibid.: 3). This then makes a case for 'libertarian paternalism', i.e. public policy to influence choices or decisions (but not by coercion) or 'nudge' people 'in a way that will make the choosers better off, as judged by themselves' (ibid.: 5).

\section{Can a wellbeing approach help us develop IGT?}

Others have taken IGT beyond the material (see in particular, Bird 2007; Harper et al. 2003; Hulme and Shepherd 2003; Kabeer 2001; Smith and Moore 2006). However, to our knowledge the 'wellbeing' approach has not been systematically applied to IGT in general or in specific examples for discussion (as we do below with nutrition).

The WeD group at Bath prior to the WeD programme certainly had a broader view of IGT on their minds. McGregor et al. (2000: 447) for example, discussed the notion of an intergenerational bargain as follows:

In all 'communities' ... there are relationships for the transfer of resources between generations and these relationships carry with them uncodified 'rights' and obligations ... [we] ... explore the transfers and processes governing transfers ... heavy emphasis has been placed on the state in securing, if not actually institutionalising the intergenerational bargain. Wide ranging changes in policy thinking and global social and economic forces require us to think more flexibly ... and see [the bargain] as a more complex interplay of state, market, community and household.

Further, in McGregor (2007: 327-32) the issue of transmission of the non-material and of meanings, culture and identities in particular is highlighted for its importance in linking needs, resources and quality of life and 'meanings' as a 'bridging' concept. This is a development of the argument in Doyal and Gough (1991) and the norms and conventions that contribute to reducing poverty over time and those that entrench it.

So, can wellbeing do anything to help address the limitations of IGT? The potential is certainly there. First, the non-material dimensions of wellbeing are essential components of transmission. In the most recent review of empirical literature on IGT, Bird (2007) argues that the determinants of IGT are split between household-level factors (household characteristics, access to productive assets, quality of parenting, nurturing and socialisation, early exposure to violence, fostering, adoption and orphanhood, child-headed households, the role of older people in IGT poverty, early childbearing, education and skill acquisition and child labour) and extra-household influences (such as conflict, cultural and psychosocial factors, class and caste, religion and ethnicity). Interestingly, many of these are non-material and are relational and subjective. The relational might include quality of parenting, nurturing and socialisation, early exposure to violence, fostering, adoption and orphanhood, class and caste, religion and ethnicity. The subjective would include early childbearing, education and skill acquisition and child labour, cultural and psychosocial factors, religion and ethnicity. The material most notably includes access to productive assets. Thus we can disrupt IGT,

via the disruption of the transmission of material wellbeing, i.e. interventions such as breastfeeding promotion to improve early childhood development, but also 
Table 2 The IGT of (individual) wellbeing: the case of nutritional status

\begin{tabular}{|c|c|c|c|}
\hline & $\begin{array}{l}\text { Material - practical } \\
\text { welfare and } \\
\text { standards of living }\end{array}$ & $\begin{array}{l}\text { Relational - personal } \\
\text { and social relations }\end{array}$ & $\begin{array}{l}\text { Subjective - values, } \\
\text { perceptions and } \\
\text { experience }\end{array}$ \\
\hline \multirow[t]{4}{*}{ What is transmitted? } & $\begin{array}{l}\text { Undernutrition as } \\
\text { measured by age- } \\
\text { specific height and } \\
\text { weight }\end{array}$ & $\begin{array}{l}\text { Time given to care- } \\
\text { provision, identity of } \\
\text { care giver }\end{array}$ & $\begin{array}{l}\text { Parental norms on } \\
\text { child height and weight }\end{array}$ \\
\hline & & $\begin{array}{l}\text { Rules about who } \\
\text { deserves the most and } \\
\text { best food in the } \\
\text { household }\end{array}$ & $\begin{array}{l}\text { The sometimes irrational } \\
\text { fear of hunger which } \\
\text { emphasises satiation over } \\
\text { diet quality }\end{array}$ \\
\hline & & & $\begin{array}{l}\text { The perception that if } \\
\text { hunger is staved off then } \\
\text { nutrition status is addressed }\end{array}$ \\
\hline & & & $\begin{array}{l}\text { Eating down in pregnancy } \\
\text { (avoiding too much weight } \\
\text { gain) }\end{array}$ \\
\hline \multirow[t]{4}{*}{ How is it transmitted? } & $\begin{array}{l}\text { Physiological mechanisms, } \\
\text { via growth in the womb }\end{array}$ & $\begin{array}{l}\text { Reinforced by extra- } \\
\text { household factors such } \\
\text { as existence and } \\
\text { quality of child care } \\
\text { facilities }\end{array}$ & $\begin{array}{l}\text { Lack of external norms } \\
\text { about healthy child size }\end{array}$ \\
\hline & $\begin{array}{l}\text { Observed allocations of } \\
\text { food, care, health, water } \\
\text { to infants }\end{array}$ & $\begin{array}{l}\text { Differential wages for } \\
\text { males and females, } \\
\text { dowry and bride price, } \\
\text { intergenerational }\end{array}$ & $\begin{array}{l}\text { Stories transmitted across } \\
\text { generations about major } \\
\text { events such as famines }\end{array}$ \\
\hline & & $\begin{array}{l}\text { transmission of property } \\
\text { rights, cultural norms }\end{array}$ & $\begin{array}{l}\text { Lack of child care } \\
\text { facilities making heavy } \\
\text { pregnancy impractical }\end{array}$ \\
\hline & & & $\begin{array}{l}\text { Observations and } \\
\text { associations between } \\
\text { relative wealth and relative } \\
\text { weight }\end{array}$ \\
\hline \multirow[t]{3}{*}{$\begin{array}{l}\text { What are the } \\
\text { determinants of } \\
\text { transmission? (i.e. the } \\
\text { mechanisms) }\end{array}$} & $\begin{array}{l}\text { Lack of information on } \\
\text { what a healthy pregnancy } \\
\text { and healthy baby look } \\
\text { like }\end{array}$ & $\begin{array}{l}\text { Lack of agency of } \\
\text { women,individually or } \\
\text { collectively, to negotiate } \\
\text { child care, gender equity } \\
\text { in food, health, water }\end{array}$ & $\begin{array}{l}\text { Inability or unwillingness to } \\
\text { interact with more diverse } \\
\text { group of people, } \\
\text { experiences, ideas }\end{array}$ \\
\hline & & $\begin{array}{l}\text { for infants, equality in } \\
\text { working conditions, in } \\
\text { property rights }\end{array}$ & $\begin{array}{l}\text { Cognitive dissonance: beliefs } \\
\text { resistant to new credible } \\
\text { and contrary evidence }\end{array}$ \\
\hline & $\begin{array}{l}\text { Extra-household/ } \\
\text { institutional features } \\
\text { which reinforce gender/ } \\
\text { ethnic biases }\end{array}$ & & $\begin{array}{l}\text { Evidence not framed in } \\
\text { ways that are compelling }\end{array}$ \\
\hline
\end{tabular}

via disruption of the transmission of subjective wellbeing, i.e. via changes in values/thinking/ consciousness and social conditioning or via the disruption of the transmission of relational wellbeing, i.e. changes in behaviour and norms, conventions, institutions. An example would 
be public policy campaigns on girls' schooling in Bangladesh relating to poor people's aspirations ('my girls will never go to school') or the multiple ways IGT is gendered by role models, values and ideas (see Tadros in this IDS Bulletin for example).

Second, the focus in wellbeing on agency makes sure we do not ignore opportunities to disrupt the transmission of illbeing/wellbeing. Lister (2004) identifies ways in which people in poverty exert agency as 'getting by' (day-to-day things people do to cope such as juggling resources), 'getting back at' (channelling of anger and despair into activities and lifestyles that signal resistance to bureaucratic and social norms), and 'getting out' (seeking routes out of poverty via officially sanctioned responses to poverty such as taking up employment or education). But as Lister argues there is also 'getting organised' (collective responses such as formation of civil society organisations, CSOs). Thus we can disrupt IGT via supporting people in 'getting organised' and mobilised via collective self-help, political action, and gendered action (Lister 2004: 155-6).

Individual agency is of course a product of wider social forces. What causes individuals to exercise their agency? And what enables that (adult's or child's) agency to affect wider social structures via (disruption) of IGT? As Lister notes (2004: 128) it is not only about how those in poverty (or children) act but also how those in power act in relation to them. What matters is not just the system of cultural norms, values, attitudes and behaviours that are transmitted across generations. More important is the degree to which people assume or identify themselves with them. Harper et al. (2003: 547) note the importance of individual agency as one of the main factors in poverty transmission and the role of attitudes and aspirations. Some new pieces of work suggest that expectations-setting and aspirations play a strong role in shaping IGT. The presence of optimism and fatalism in aspirations appears in many of the studies of chronic poverty as a key element of IGT. Some authors have proposed that these psychosocial factors might be working as additional reinforcement mechanisms. Particularly, a circle of low (or frustrated) aspirations and endemic poverty may be a self-sustaining outcome (Appadurai 2004; Ray 2006). Bird (2007: ix) in her empirical review of IGT also notes, 'low aspirations probably contribute to reduced income and asset formation and may influence parenting patterns and investment decisions (including in children's human capital formation) thus contributing to IGT poverty'.

\section{An application to undernutrition transmission}

To further explore these two potential areas of wellbeing's value added to IGT - the focus on the relational and perceptual dimensions of poverty and the emphasis on agency - and to give a concrete example, we focus on the transmission of nutrition status from one generation to another.

Nutrition matters not only in its own right and with regard to health but also plays a large role in education and various other dimensions of poverty and wellbeing. ${ }^{6}$ In terms of IGT, the priority period for investment is while the child is in the womb and up to 18 months of age.

Malnutrition losses incurred during this period cannot be retrieved by interventions introduced after the first 18 months of life - they represent losses the child will carry throughout life. Of the female babies who survive, the ones who remain malnourished in adolescence are more likely, in turn, to give birth to malnourished babies. This is the mechanism - a physiological one - that tends to get highlighted in mainstream nutrition conversations, but there are others. Can the wellbeing lens help us think differently about how to break the IGT of nutritional status? We take the individual row of White's (2008) framework from Table 1 and Moore's (2001). What is transmitted, how is it transmitted and what determines transmission to generate Table 2.

Several things are worth noting from Table 2. First, the wellbeing framework has not identified any issues that the nutrition community as a whole would not have known about or thought about. Issues of behaviour change; the links between intra- and extra-household factors and focus on relationships are not new. This failure to unearth anything new at this level may of course be due to our lack of facility with using this framework, but we feel we would be fairly typical of an interested newcomer to the field, trying to apply it to an area of our expertise.

Second, the wellbeing framework will, however, link different schools of thought. The 'nutrition as food' school tend to focus more on the material. 
The 'nutrition as care' school focuses more on relations. The 'nutrition as health' school is a mix of material, relational and perceptual. This linkage - conceptual and potentially operational is essential if undernutrition is to be tackled at scale (see for discussion The Lancet 2008 special issue on this subject).

Finally, from a nutrition perspective, perhaps the greatest value added for us is in the perceptual column and the 'determinants' of transmission row. Perceptions are recognised - up to a point as important in the health profession establishment, but less so in agriculture development and economics professions. Little attention is given to understanding farmer views, to farmer mobilisation and the IGT of skills and stories. The determinants row in the relational and perceptions columns takes analysis and action into fundamental issues of law, culture, political agency and ideas of epistemic communities, self-maintaining mindsets and the different ways of constructing knowledge and realities. A failure to understand and reconcile the different ways in which different stakeholders frame, prioritise, assess risk and regulate their actions is often at the heart of inaction.

\section{Conclusions}

The intergenerational transmission of poverty is a well-established conceptualisation of how poverty is reproduced over time. IGT has been a popular approach because of its focus beyond poverty measurement to how poverty is

\section{Notes}

1 Indeed, Corak's (2006) study of new data and review of all existing studies on nine developed countries argued IGT (via proxy of income) transmission is by no means certain just far more likely in more (income) unequal countries. These findings are consistent with the earlier Yaqub (2002) review that has a more development focus albeit with empirical literature from developed countries.

2 There is also the UNU Inequality, Poverty and Wellbeing project at the WIDER, Helsinki (see McGillivray 2006; McGillivray and Clarke 2006). See respectively www.welldev.org.uk and www.wider.unu.edu/research/projects-bytheme (both accessed 18 October 2008).

3 The inclusion of community wellbeing as well as individual wellbeing is important because the WeD group found that the relational and reproduced (or not) over time. But as currently constructed it tends to be overly deterministic and to overly emphasise material assets. In contrast, 'wellbeing' is emerging as a complement to the more traditional ways of conceptualising and measuring poverty and deprivation around material consumption. Wellbeing extends attention from what people can do and be to how people feel about what they can do and be. Wellbeing is thus explicitly rather than inferentially about agency and also goes beyond the material to consider the relational and the subjective domains of life.

Therefore, can a wellbeing lens help us to rethink IGT? We conclude it can, but we urge caution. Our conclusion is based upon our application of wellbeing concepts to a particular type of IGT mechanism - the transmission of undernutrition from mother to child at an individual level (one generation to the next). We find the wellbeing application provides the potential to connect different public policy approaches to the IGT of undernutrition (i.e. Copestake's (2008) 'mental map') - something that is vitally lacking, resulting in a lack of effective coordinated action to accelerate reductions in undernutrition.

Relatedly, the wellbeing approach will also help to unpack the plurality of views outside public policy circles on what nutrition status is and how it is overcome. Coordinating different public policy approaches while helping engagement with the diversity of views at the micro level will help make nutrition actions more effective.

the community aspects of wellbeing was particularly emphasised in the developing countries they studied but they did not compare this with work in the developed countries. 'Relatedness' in people's lives was central for wellbeing. Further, there was often a strong moral aspect of subjective wellbeing related to collective aspects of wellbeing and the community not just to individual preferences.

4 Appadurai (2004), for example, argues that aspirations and values are born in the thick of social life.

5 See also McGregor (2004: 349-52; 2007 : 347-50).

6 Child malnutrition is responsible for up to a third of all child and infant mortality and is a leading cause of disease. Chronic malnutrition affects billions of people. One in three infants 
in South Asia and sub-Saharan Africa are chronically malnourished. In South Asia the number of children under five who are low weight-for-age or low height-for-age is steadily declining - albeit with several countries still showing increases - but in sub-Saharan Africa the number is steadily increasing even at the regional level: child malnutrition is responsible for half of all child deaths, and infant and maternal malnutrition are leading causes of disease. Malnutrition is the leading cause of disease (Sumner et al. 2007).

\section{References}

Altonji, J.G.; Hayashi, F. and Kotlikoff, L.J. (1997) 'Parental Altruism and Inter Vivos Transfers: Theory and Evidence', Journal of Political Economy 105/6: 1121-66

Appadurai, A. (2004) 'The Capacity to Aspire: Culture and the Terms of Recognition', in Vijayendra Rao and Michael Walton (eds), Culture and Public Action, Stanford: Stanford University Press

Ariely, D. (2008) Predictably Irrational: The Hidden Forces that Shape Our Decisions, London: HarperCollins

Bird, K. (2007) The Intergenerational Transmission of Poverty: An Overview, CPRG Working Paper 99, London and Manchester: Chronic Poverty Research Centre

Castañeda, T. and Aldaz-Carroll, E. (1999) The Intergenerational Transmission of Poverty: Some Cause and Policy Implications, Discussion Paper, Washington DC: Inter-American Development Bank

Copestake, J. (2008) 'Wellbeing in International Development: What's New?', Journal of International Development 20.5: 577-97

Corak, M. (2006) Do Poor Children Become Poor Adults? Lessons from a Cross Country Comparison of Generational Earnings Mobility, IZA Discussion Papers 1993, Bonn: Institute for the Study of Labor

Coyle, D. (2007) The Soulful Science: What Economists Really Do and Why It Matters, Princeton: Princeton University Press

Doyal, L. and Gough, I. (1991) A Theory of Human Need, London: Macmillan

Fraser, N. (2000) 'Rethinking Recognition', New Left Review 3: 107-20

Gough, I. and McGregor, J.A. (eds) (2007) Wellbeing in Developing Countries, Cambridge: Cambridge University Press

Harper, C.; Marcus, R. and Moore, K. (2003)

'Enduring Poverty and the Conditions of Childhood: Lifecourse and Intergenerational Poverty Transmissions', World Development 31.3: 535-54

Hulme, D. and Shepherd, A. (2003)

'Conceptualizing Chronic Poverty', World Development 31.3: 403-23

Kabeer, N. (2001) 'Intergenerational Contracts, Demographic Transitions and the "QuantityQuality" Trade-off: Children, Parents and Investing in the Future', Journal of International Development 12.4: 463-82

The Lancet (2008) Maternal and Child Undernutrition Series 371.9612: 243-526

Lister, R. (2004) Poverty, Cambridge: Polity Press McGillivray, M. (2006) Human Well-being: Concept and Measurement, New York: Palgrave Macmillan

McGillivray, M. and Clarke, M. (2006) Understanding Human Well-being, New York: United Nations University Press

McGregor, J.A. (2007) 'Researching Wellbeing: From Concepts to Methodology,' in I. Gough and J.A. McGregor (eds), Wellbeing in Developing Countries, Cambridge: Cambridge University Press

McGregor, J.A. (2004) 'Researching Well-being: Communicating Between the Needs of Policy Makers and the Needs of People,' Global Social Policy 4.3: 337-58

McGregor, J.A.; Copestake, J.G. and Wood, G.D. (2000) 'Editorial: The Intergenerational Bargain', Journal of International Development 12.4: 447-51

Moore, K. (2001) Frameworks for Understanding the Inter-Generational Transmission of Poverty and Wellbeing in Developing Countries, CPRC Working Paper 8, Manchester: Chronic Poverty Research Centre

Ray, D. (2006) 'Aspirations, Poverty and Economic Change', in A. Banerjee, R. Banabou and D. Mookherjee (eds), Understanding Poverty, New York: Oxford University Press 409-21

Sen, A. (1999) Development as Freedom, New York: Oxford University Press

Smith, B. and Moore, K. (2006) Intergenerational Transmission of Poverty in Sub-Saharan Africa, CRPG Working Paper 59, Manchester: Chronic Poverty Research Centre 
Sumner, A.; Lindstrom, J. and Haddad, L. (2007) Greater DFID and EC Leadership on Chronic Malnutrition: Opportunities and Constraints, Brighton: IDS

Thaler, R. and Sunstein, C. (2008) Nudge: Improving Decisions About Health, Wealth and Happiness, New Haven and London: Yale University Press White, S.C. (2008) But What is Wellbeing? A Framework for Analysis in Social and Development
Policy and Practice, WeD Working Paper 43, Bath: Wellbeing in Developing Countries ESRC Research Group, University of Bath Yaqub, S. (2002) 'Poor Children Grow into Poor Adults: Harmful Mechanisms or Overdeterministic Theory?', Journal of International Development 14.8: 1081-93 